\title{
Assessment of Physicians' Knowledge, Attitude and Practices of Radiation Safety at Suez Canal University Hospital, Egypt
}

\author{
Rasha F. Abdellah, Shaimaa A. Attia, Ahmed M. Fouad, Amani W. Abdel-Halim \\ Community Medicine Department, Faculty of Medicine, Suez Canal University, Ismailia, Egypt \\ Email: Rashaf11@yahoo.com
}

Received 29 November 2015; accepted 26 December 2015; published 29 December 2015

Copyright () 2015 by authors and Scientific Research Publishing Inc.

This work is licensed under the Creative Commons Attribution International License (CC BY). http://creativecommons.org/licenses/by/4.0/

(c) (i) Open Access

\begin{abstract}
Doctors who request imaging must be well trained in deciding whether diagnostic imaging is indicated and have an accurate knowledge of the associated risks. Although radiological doses are low and the chance of late effect is minimal, it should be kept as low as reasonably achievable. This cannot be achieved without a proper knowledge and adherence to safe practices. This cross-sectional study investigates the level of physicians' knowledge about radiation safety and their attitude towards radiation protection. A self-administered questionnaire, for radiation safety was sent to a purposive sample of 120 physicians at Suez Canal University Hospital. Eighty questionnaires were filled by participants (response rate; $66.7 \%$ ). The sample included 22 radiologists, 15 oncologists, 25 surgeons and 18 orthopedists. Most participants did not receive any radiation safety-related training (88.8\%). Radiologists and oncologists were exposed to ionizing radiation more frequently; however, their knowledge was as low as that of other physicians. The overall knowledge score ranged from $40 \%-60 \%$ (mean; $56.5 \pm 15.2$ ), with a low score among surgeons and orthopedics. The most deficient knowledge was in the dose of background radiation and the radiation dose received by patients in each type of radiation procedure. Adherence to safe radiation practices was violated by most of participants, especially surgeons and orthopedics, but they attributed it to the poor applicability of the protective measures during performing the procedures. This study concluded that physicians at the Suez Canal University Hospital had deficient knowledge, unsafe practices and negative attitude towards radiation safety policies $\&$ precautions.
\end{abstract}

\section{Keywords}

Physicians' Knowledge, Attitude, Practice, Radiation Safety 


\section{Introduction}

Diagnostic imaging and interventional radiological techniques are increasingly used to diagnose a wide range of injuries and diseases, and to give life-saving treatment for many diseases. The use of radiation in medical practices has evolved since its beginning and $30 \%$ to $50 \%$ of medical decisions are based on radiological examinations. However, it is still limited by its relevant hazards to patients and healthcare providers [1] [2].

CT comprises $4 \%$ of examinations; it makes a $40 \%$ contribution to the collective dose of radiation Ionizing radiation causes genetic damage, which is linked to cancer induction, but this varies depending on the duration and the dose of exposure [3] [4]. The average radiation dose received annually by the public is $2.5 \mathrm{mSv}$, and $15 \%$ of them are related to medical exposures [1]. Among all radiological examinations, the doses of CT are the highest. The typical exposure dose for an abdominal CT is $9 \mathrm{mSv}$ and that for one chest radiograph is $0.02 \mathrm{mSv}$ [5].

The dose of radiation given in any diagnostic procedure should be enough to answer the relevant clinical question, but as low as reasonably achievable to lower the risk to the patient [6]. Therefore, it is important that doctors who request imaging are well-trained in deciding the diagnostic imaging indicated, and have an accurate knowledge of the associated risks [7]. Unfortunately, the studies show that there is a widespread underestimation of radiation doses among pediatricians and physicians [5].

An understanding of radiation safety principles and their application in practice are critical for all health care workers. However, misconceptions about radiation are common, causing fear and concerns that may negatively impact patient care [8]. Previous studies have shown that physicians tend to underestimate the risks to patients of radiation exposure [9].

The level of awareness concerning radiation protection influences the staff behavior. If they have not enough information related to radiation safety, their action will not be safe and be resulted in adverse effects [10]. Our current challenges will not be to address new policies and procedures, but we need a better understanding of the frequency and causes of errors, particularly those that are most likely to cause harm. The goal is not to eliminate all errors; rather, we should focus our attention on conditions that can cause real harm, and/or those conditions that reflect systemic problems that may lead to errors more likely to cause harm [11] [12].

A number of surveys concerning this issue have been conducted among health care professionals in America and Europe. Studies on African doctors' awareness of radiation dose are lacking. Therefore, it is extremely important to consider the safety of both the patient and the medical professional performing the radiological procedure. This study aims to assess physicians' knowledge, attitude and practices regarding radiation safety in Suez Canal University Hospital.

\section{Materials and Methods}

This cross-sectional study was conducted in Suez Canal university hospital, Egypt during August-September, 2015. Confidentiality and anonymity were maintained according to the regulations mandated by Research Ethics Committee of Faculty of Medicine Suez Canal University, in accordance with the Declaration of Helsinki.

\subsection{Subjects}

Recruitment was done by convenience sampling of all physicians exposed to ionizing radiation in radiology, oncology, surgery and orthopedics departments on a voluntary basis. The participants were informed that the results would be used only for a scientific study.

\subsection{Questionnaire}

A self-administered questionnaire was sent to all 120 eligible physicians and asked to fill and return it within two weeks (Appendix). They were asked about their duration of employment, training in radiation safety, exposure characteristics, knowledge, attitude and practices of radiation safety. The questionnaire was tested on 10 physicians in a pilot survey and we excluded these 10 physicians from the study.

\subsection{Statistical Analysis}

Statistical analysis was performed using the Statistical Package for the Social Sciences for windows (SPSS 18.0) 
descriptive statistics including frequency distribution, mean, standard deviation and percentages. Level of knowledge, attitude and practices were calculated as a percentage of correct answers in each section. Levels less than $50 \%$ were considered poor knowledge, unsafe practices or negative attitude.

\section{Results}

Eighty questionnaires were filled by participants (response rate; 66.7\%). The participants included 22 radiologists, 15 oncologists, 25 surgeons and 18 orthopedists. The mean age of participants was $29.85 \pm 3.84$ years and ranged from 25 - 40 years. Male physicians represented $81.3 \%$ of participants compared to $18.7 \%$ females. The mean duration of current employment among participating physicians was $5.85 \pm 3.84$ years; ranged from 1 - 16 years (Table 1).

The majority of physicians (88.8\%) didn't receive any radiation safety training, and $80.0 \%$ of them didn't use to read about radiation safety (Table 1). Fifty six physicians (70.0\%) were exposed to ionizing radiation once/ week or more, while only 30.0\% was exposed to ionizing radiation less than once/week (Table 2). Only 46 physicians (57.5\%) were adherent to radiation protection policies, procedures and personal protective equipment (PPE). At least $52.5 \%$ of physicians thought that radiation protection policies, procedures and PPE were applicable and convenient while working. However, the 28 physicians (35\%) were standing at a distance of two meters or less from source point without protection (Table 2).

Regarding physicians' knowledge, 60\% correctly identified the background radiation equivalent dose and $63.8 \%$ correctly identified the radiation equivalent dose in chest X-ray. However, only $30.0 \%, 17.5 \%$, 35.0\% and $72.5 \%$ of physicians correctly identified the equivalent number of chest X-rays in different radiological investigations (X-ray, CT, MRI and Ultrasound respectively) (Table 3).

In Table 4, 65\% of physicians thought that policies and procedures for radiation protection in their hospital were clear and easily understood, while $61.3 \%$ thought they were confident about the radiation protection precautions. Forty seven physicians (58.8\%) knew whom to contact if they have any questions regarding radiation protection, and $50.0 \%$ felt they can clearly explain precautions required for caring their patients and visitors. Moreover, only $27.5 \%$ felt safe while caring their patients needing radiological investigations, and $35 \%$ felt that policies and procedures in the hospital were based on up to date regulations. Finally, only $15 \%$ felt confident that their institution carefully monitor their exposure to radiation.

The mean knowledge percent score was $56.5 \pm 15.2$ and ranged from $40 \%-60 \%$. 76.3\% of physicians were

Table 1. Distribution of physicians according to personal \& work characteristics $(\mathrm{N}=80)$.

\begin{tabular}{cc} 
Age (year): & \\
Mean \pm SD & $29.85 \pm 3.84$ \\
Range & $25-40$ \\
Sex: & $65(81.3 \%)$ \\
Male & $15(18.7 \%)$ \\
Female & \\
Department: & $22(27.5 \%)$ \\
Radiology & $15(18.8 \%)$ \\
Oncology & $25(31.2 \%)$ \\
Surgery & $18(22.5 \%)$ \\
Orthopedics & \\
Duration of current employment (year) & $5.85 \pm 3.84$ \\
Mean \pm SD & $1-16$ \\
Range & $9(11.2 \%)$ \\
Receiving radiation safety training (Yes) & $16(20.0 \%)$ \\
\hline
\end{tabular}


Table 2. Distribution of physicians according to their exposure and practices $(\mathrm{N}=80)$.

\section{Exposure frequency (/week):}

Less than once/week

$$
1 \text { - } 3 \text { times/week }
$$

More than 3 times/week

Adherence to radiation protection policies, procedures \& PPE:

$\begin{array}{cr}\text { Adherent } & 46(57.5 \%) \\ \text { Not adherent } & 34(42.5 \%)\end{array}$

Applicability \& convenience of radiation protection policies, procedures \& $\mathrm{PPE}^{1}$ :

\begin{tabular}{|c|c|}
\hline Lead aprons & $50(62.5 \%)$ \\
\hline Leaded gloves & 42 (52.5\%) \\
\hline Minimal procedure time & $52(65.0 \%)$ \\
\hline Increasing distance from $x$-ray device & $48(60.0 \%)$ \\
\hline
\end{tabular}

Distance from radiological device without protection during the procedure (meter)
Less than 1 meter
$3(3.7 \%)$
1 - 2 meters
$25(31.3 \%)$
More than 2 meters
$52(65.0 \%)$

${ }^{1} \mathrm{PPE}=$ Personal Protective Equipment.

Table 3. Distribution of physicians' knowledge regarding radiation dose $(\mathrm{N}=80)$.

\section{Radiation dose:}

Background radiation dose (mSv)

Chest X-ray radiation dose (mSv)
No. (\%) of correct answers

$48(60.0 \%)$

$51(63.8 \%)$

Equivalent number of chest $x$ rays in radiological investigations:

$\begin{array}{cc}\text { X ray } & 24(30.0 \%) \\ \text { CT } & 14(17.5 \%) \\ \text { MRI } & 28(35.0 \%) \\ \text { Ultrasound } & 58(72.5 \%)\end{array}$

Table 4. Distribution of physicians according to attitude regarding radiation safety $(\mathrm{N}=80)$.

\begin{tabular}{|c|c|c|}
\hline & & No. $(\%)$ of agree response \\
\hline 1) & Policies \& procedures on radiation precautions are clear and easy to understand. & $52(65.0 \%)$ \\
\hline 2) & $\begin{array}{l}\text { I feel confident about the steps I need to take when caring for patients needing radiation } \\
\text { precautions. }\end{array}$ & $49(61.3 \%)$ \\
\hline 3) & $\begin{array}{l}\text { I know whom to contact if I have questions about what radiation precautions are needed for a } \\
\text { particular patient. }\end{array}$ & $47(58.8 \%)$ \\
\hline 4) & I feel I can clearly explain the radiation precautions needed to my patients and their visitors. & $40(50.0 \%)$ \\
\hline 5) & I feel safe when caring for patients needing radiation precautions. & $22(27.5 \%)$ \\
\hline 6) & I feel the institutional policies and procedures are based on current regulations. & $28(35.0 \%)$ \\
\hline 7) & I feel confident the institution is carefully monitoring my radiation exposure. & $12(15.0 \%)$ \\
\hline
\end{tabular}

classified as having poor knowledge, while only $23.7 \%$ was classified as having fair to good knowledge. Moreover, the mean attitude percent score was $46.9 \pm 8.6$ and ranged from $22 \%$ - 65\%. The greater proportion (76.3\%) 
of participants had a negative attitude while only $23.7 \%$ had a positive attitude toward radiation safety policies and precautions in the hospital. On the other hand, the mean practice percent score was $59.3 \pm 10.5$; ranged from $35 \%-67 \%$; $58.8 \%$ was classified as having unsafe practices while $41.2 \%$ was classified as having safe practices (Table 5).

\section{Discussion}

The exposure to radiation from medical procedures has become a topic of recent public and scientific discussion. Our study results align with previous studies that physician's knowledge and practice toward radiation exposure is poor [3] [5]. The physician should be knowledgeable on radiation protection properly protect themselves, the patients, and others around the patients.

Our results show that only $11.2 \%$ of physicians received radiation safety training and only $20.0 \%$ of them read about radiation safety. A higher rate of the respondents (55\%) had attended an education program in Europe about radiation safety and the attendance was highest in Poland (82.6\%) [13] [14]. As regards exposure frequency, $37.5 \%$ of participants reported more than three times exposure/week. In a study conducted on urology residents in 20 different European countries, all of the participants reported that they were routinely exposed to ionizing radiation and $72.5 \%$ were exposed more than 3 times per week [13].

Regarding physicians' knowledge, our study revealed that $60 \%$ of physicians correctly identified the background radiation equivalent dose and $63.8 \%$ correctly identified the radiation equivalent dose in chest X-ray. However, only $30.0 \%, 17.5 \%, 35.0 \%$ and $72.5 \%$ of physicians correctly identified the equivalent number of chest X-rays in different radiological investigations (X-ray, CT, MRI and Ultrasound respectively). In United Kingdom, 22\% - 24\% of all physicians kwon the correct dose of a conventional adult chest radiograph [15]. However, in the study conducted by Shiralkar et al. no participant knew the correct dose [16]. In Germany, 59\% of participants in a survey, estimated the dose of adult chest radiograph correctly and only $5 \%$ underestimating it [17].

In Turkey, total of $41.4 \%$ of all participants and $46.3 \%$ of resident doctors underestimated the radiation doses [18]. While in China, all non-radiologists physicians cannot correctly state the radiation dose (in mSv) of a conventional chest X-ray, and 77\% underestimated the dose of radiological examinations. For radiologists, only 32\% were correct for the radiation dose of a conventional chest X-ray while $7 \%$ underestimated the radiation doses [19]. Underestimation of radiation dose means that physicians are not aware of the radiation risks and they are less cautious in offering radiation related investigations to their patients, which in turn may increase their unnecessary exposure [13]. Also, there are physicians failing to recognize that MR and US as radiation-free modalities, these alternatives to X-ray and CT may not be fully utilized in their practices.

According to the present study, physicians used lead aprons more than they did other PPE and only, 52.5\% used lead gloves. The use of other measures, such as thyroid shields and eyeglasses were less frequent than

Table 5. Distribution of physicians' score of knowledge, attitude and practices regarding radiation safety $(\mathrm{N}=80)$.

$\begin{array}{cc}\text { Knowledge score: } & \\ \text { Mean } \pm \text { SD; (Range) } & 56.5 \pm 15.2 ;(40 \%-60 \%) \\ \text { Poor knowledge } & 61(76.3 \%) \\ \text { Fair/good knowledge } & 19(23.7 \%) \\ \text { Attitude score } & \\ \text { Mean } \pm \text { SD; (Range) } & 46.9 \pm 8.6 ;(22 \%-65 \%) \\ \text { Negative attitude } & 61(76.3 \%) \\ \text { Positive attitude } & 19(23.7 \%) \\ \text { Practices score } & \\ \text { Mean } \pm \text { SD; (Range) } & 59.3 \pm 10.5 ;(35 \%-67 \%) \\ \text { Unsafe practices } & 47(58.8 \%) \\ \text { Safe practices } & 33(41.2 \%)\end{array}$


expected. The results of Friedman et al suggest that the use of the body and thyroid shields was high (99\% and $73 \%$, respectively) and no one used lead-lined glasses and gloves [14].

The mean knowledge percent score was $56.5 \pm 15$.2. About seventy-six percent of physicians were classified as having poor knowledge, while only $23.7 \%$ were classified as having fair to good knowledge. Moreover, the mean attitude percent score was $46.9 \pm 8.6$. On the other hand, the mean practice percent score was $59.3 \pm 10.5$ and $58.8 \%$ were classified as having unsafe practices. In Australia, the mean doctors' knowledge of patient radiation exposure from diagnostic imaging requested in the emergency department was 40\% (95\% CI, 38\% - 43\%) [20].

Many factors were contributed to the poor knowledge scores achieved in this study. The undergraduate never having formal training on this topic. The deficit of knowledge of basic scientific principles in postgraduate education and no organized continuous education in hospitals on radiation protection. In addition, there were inadequate availability of radiation safety equipment as radiation dose badges and this may be one of the major reasons for not using them. There was no regular monitoring of radiation exposure per year and therefore, it is difficult to assess the average radiation exposure in hospitals [21] [22]. We thought that the following solutions would improve the knowledge of physicians: 1) Provide a guide to good use of imaging tests; 2) Schedule continuing medical education on radiation protection in hospital practice; 3) Integrate in the initial medical training school, courses on radiation protection [23] [24].

A limitation of this research is that it was a self-administered questionnaire based study; therefore, responders may have answered some questions after checking for the correct answers. The small number of responders (response rate; 66.7\%) represent another limitation. Further studies with larger populations will provide further insights into this issue.

\section{Conclusion}

At Suez Canal University Hospital, physicians' knowledge and practices toward radiation safety related to radiological imaging are poor. Training programs can significantly improve doctors' awareness and knowledge in this aspect.

\section{Acknowledgements}

I would like to express my sincere appreciation and deepest gratitude for the cooperation and generous help of the participants and the responsible authorities in Suez Canal University Hospital in Ismailia.

\section{References}

[1] Sani, K., Jafari, M., Mohammadi, M., Mojiri, M. and Rahimi, A. (2009) Iranian Physicians’ Knowledge about Radiation Dose, Received by Patients in Diagnostic Radiology. Iranian Journal of Radiation Research, 6, 207-212.

[2] O’Sullivan, J., O’Connor, J., O’Regan, K., Clarke, B., Burgoyne, L., Ryan, M. and Maher, M. (2010) An Assessment of Medical Students' Awareness of Radiation Exposures Associated with Diagnostic Imaging Investigations. Insights into Imaging, 1, 86-92. http://dx.doi.org/10.1007/s13244-010-0009-8

[3] Yurt, A., Çavuşoğlu, B. and Günay, T. (2014) Evaluation of Awareness on Radiation Protection and Knowledge about Radiological Examinations in Healthcare Professionals Who Use Ionized Radiation at Work. Molecular Imaging and Radionuclidetherapy, 23, 48-53. http://dx.doi.org/10.4274/mirt.00719

[4] Arslanoğlu, A., Bilgin, S., Kubal, Z., Ceyhan, M.N., Ilhan, M.N. and Maral, I. (2007) Doctors’ and Intern Doctors’ Knowledge about Patients’ Ionizing Radiation Exposure Doses during Common Radiological Examinations. Diagnostic and Interventional Radiology, 13, 53-55.

[5] Wong, C.S., Huang, B., Sin, H., Wong, W., Yiu, K. and Chu, Y. (2012) A Questionnaire Study Assessing Local Physicians, Radiologists and Interns’ Knowledge and Practice Pertaining to Radiation Exposure Related to Radiological Imaging. European Journal of Radiology, 81, 264-268. http://dx.doi.org/10.1016/j.ejrad.2011.02.022

[6] Keijzers, G.B. and Britton, C.J. (2010) Doctors’ Knowledge of Patient Radiation Exposure from Diagnostic Imaging Requested in the Emergency Department. Medical Journal of Australia, 193, 450-453.

[7] Moifo, B., Edzimbi, A., Tebere, H., Tambe, J., Samba, R. and Fotsin, J. (2014) Referring Physicians’ Knowledge on Justification of Medical Exposure in Diagnostic Imaging in a Sub-Saharan African Country, Cameroon. Open Journal of Radiology, 4, 60-68. http://dx.doi.org/10.4236/ojrad.2014.41008

[8] Dauer, L.T., Kelvin, J.F., Horan, C.L. and St Germain, J. (2006) Evaluating the Effectiveness of a Radiation Safety 
Training Intervention for Oncology Nurses: A Pretest-Intervention-Posttest Study. BMC Medical Education, 6, 32. http://dx.doi.org/10.1186/1472-6920-6-32

[9] Hamarsheh, A. and Ahmead, M. (2012) Assessment of Physicians' Knowledge and Awareness about the Hazards of Radiological Examinations on the Health of Their Patients. EMHJ, 18, 875-881.

[10] Prabhat, M., Sudhakar, S., Kumar, B. and Ramaraju, P. (2011) Knowledge, Attitude and Perception (KAP) of Dental Undergraduates Interns on Radiographic Protection-A Questionnaire Based Cross-Sectional Study. Journal of Advanced Oral Research, 2, 45-50.

[11] Marks, L.B., Jackson, M., Xie, L., Chang, S.X., Burkhardt, K.D., Mazur, L., Jones, E.L., Saponaro, P., LaChapelle, D., Baynes, D.C. and Adams, R.D. (2011) The Challenge of Maximizing Safety in Radiation Oncology. Practical Radiation Oncology, 1, 2-14. http://dx.doi.org/10.1016/j.prro.2010.10.001

[12] Yurt, A., Çavuşoğlu, B. and Günay, T. (2014) Evaluation of Awareness on Radiation Protection and Knowledge about Radiological Examinations in Healthcare Professionals Who Use Ionized Radiation at Work. Molecular Imaging and Radionuclide Therapy, 23, 48-53. http://dx.doi.org/10.4274/mirt.00719

[13] Söylemez, H., Sancaktutar, A.A., Silay, M.S., Penbegül, N., Bozkurt, Y., Atar, M., Altunoluk, B., Bodakci, M.N. and Hatipoglu, N.K. (2013) Knowledge and Attitude of European Urology Residents about Ionizing Radiation. Urology, 81, 30-35. http://dx.doi.org/10.1016/j.urology.2012.07.097

[14] Friedman, A.A., Ghani, K.R., Peabody, J.O., Jackson, A., Trinh, Q.D. and Elder, J.S. (2013) Radiation Safety Knowledge and Practices among Urology Residents and Fellows: Results of a Nationwide Survey. Journal of Surgical Education, 70, 224-231. http://dx.doi.org/10.1016/j.jsurg.2012.10.002

[15] Soye, J.A. and Paterson, A. (2008) A Survey of Awareness of Radiation Dose among Health Professionals in Northern Ireland. The British Journal of Radiology, 81, 725-729. http://dx.doi.org/10.1259/bjr/94101717

[16] Shiralkar, S., Rennie, A., Snow, M., Galland, R.B., Lewis, M.H. and Gower-Thomas, K. (2003) Doctors' Knowledge of Radiation Exposure: Questionnaire Study. BMJ, 327, 371-372. http://dx.doi.org/10.1136/bmj.327.7411.371

[17] Heyer, C.M., Hansmann, J., Peters, S.A. and Lemburg, S.P. (2010) Paediatrician Awareness of Radiation Dose and Inherent Risks in Chest Imaging Studies-A Questionnaire Study. European Journal of Radiology, 76, 288-293. http://dx.doi.org/10.1016/j.ejrad.2009.06.014

[18] Günalp, M., Gülünay, B., Polat, O., Demirkan, A., Gürler, S., Akkaş, M. and Aksu, N.M. (2014) Ionising Radiation Awareness among Resident Doctors, Interns, and Radiographers in a University Hospital Emergency Department. La Radiologia Medica, 119, 40-47. http://dx.doi.org/10.1007/s11547-013-0374-8

[19] Lee, R.K., Chu, W.C., Graham, A., Rainer, T.H. and Ahuja, A.T. (2012) Knowledge of Radiation Exposure in Common Radiological Investigations: A Comparison between Radiologists and Non-Radiologists. Emergency Medicine Journal, 29, 306-308. http://dx.doi.org/10.1136/emermed-2011-200481

[20] Keijzers, G.B. and Britton, C.J. (2010) Doctors’ Knowledge of Patient Radiation Exposure from Diagnostic Imaging Requested in the Emergency Department. Medical Journal of Australia, 193, 450-453.

[21] Rahman, N., Dhakam, S., Shafqut, A., Qadir, S. and Tipoo, F. (2008) Knowledge and Practice of Radiation Safety among Invasive Cardiologists. Journal of Pakistan Medical Association, 58, 119-122.

[22] Ahidjo, A., Garba, I., Mustapha, Z., Abubakar, A.M. and Usman, U.A. (2012) Referring Doctors Knowledge about Radiation Doses in Patients Undergoing Common Radiological Examinations. Journal of Medicine and Medical Science, 3, 222-225.

[23] Moifo, B., Edzimbi, A., Tebere, H., Tambe, J., Samba, R. and Fotsin, J. (2014) Referring Physicians’ Knowledge on Justification of Medical Exposure in Diagnostic Imaging in a Sub-Saharan African Country, Cameroon. Open Journal of Radiology, 4, 60-68. http://dx.doi.org/10.4236/ojrad.2014.41008

[24] Zewdneh, D., Dellie, S. and Ayele, T. (2012) Study of Knowledge \& Awareness of Medical Doctors towards Radiation Exposure Risk at Tikur Anbessa Specialized Referral and Teaching Hospital, Addis Ababa, Ethiopia. IOSR Journal of Pharmacy and Biological Sciences, 2, 1-5. http://dx.doi.org/10.9790/3008-0240105 


\section{Appendix}

\section{Radiation Safety Survey}

1) Name:

2) Contact: Tel:

e-mail:

3) Age:

4) Date of graduation:

5) Job category:

a) Radiologist

b) Oncologist

c) Clinician (Specialty:

d) Technician

e) Nurse

6) Duration of work/current employment (years):

7) Did you take any radiation safety training?

a) No

b) Yes

8) Have you ever read a medical article about radiation safety? If yes how many?

a) No

b) Yes, 1 article

c) Yes, 1 - 5

d) Yes, $>5$

9) How often do you expose to radiation every week?

a) More than 3 times/week

b) 1 - 3 times/week

c) Less than one time per week

d) I do not expose to radiation

10)How often do you use the following radiation protection policies/equipment, during radiological procedures?

\begin{tabular}{|c|c|c|c|c|c|}
\hline & Never & Sometimes & Generally & Always & No ideas \\
\hline \multicolumn{6}{|l|}{ Lead aprons } \\
\hline \multicolumn{6}{|l|}{ Thyroid shields } \\
\hline \multicolumn{6}{|l|}{ Leaded gloves } \\
\hline \multicolumn{6}{|l|}{ Eye glasses } \\
\hline \multicolumn{6}{|l|}{ Use minimal endoscopic time } \\
\hline Increasing distance from $x$-ray device & & & & & \\
\hline
\end{tabular}

11)How far from the X-ray, do you stand without any protection during the radiological-guided procedure (e.g. C-arm)?

a) 1 meter

b) 2 meters

c) 5 meters

d) I always use in operating room

e) I do not care the radiation

12)What do think about applicability \& practical use of protective clothes listed below?

\begin{tabular}{cccccc}
\hline & Very good & Good & Bad & Very bad & No ideas \\
\hline Lead aprons & & & \\
Thyroid shields & & & \\
Leaded gloves & & \\
Eye glasses & & \\
\hline
\end{tabular}


13)How much radiation, in milli-Sieverts (mSV), is a person exposed to, on average, every year, from natural background radiation:

a) 0.24

b) 2.4

c) 24

d) 240

e) I have no idea

14)What is the approximate radiation dose, in (mSv), of a chest $x$-ray?

a) 0.02

b) 0.2

c) 2

d) 20

e) I have no idea

15)Please score the following four organs in order of radiation sensitivity.

\begin{tabular}{|c|c|c|c|c|c|}
\hline & Very insensitive & Insensitive & Sensitive & Sensitive & No ideas \\
\hline \multicolumn{6}{|l|}{ Bladder } \\
\hline \multicolumn{6}{|l|}{ Gonads } \\
\hline \multicolumn{6}{|l|}{ Kidneys } \\
\hline \multicolumn{6}{|l|}{ Skin } \\
\hline \multicolumn{6}{|l|}{ CNS } \\
\hline \multicolumn{6}{|c|}{ Bone Marrow } \\
\hline \multicolumn{6}{|l|}{ Thyroid } \\
\hline GIT & & & & & \\
\hline
\end{tabular}

16)If a chest $X$-ray is counted as a 1 unit, how many units would a patient absorb in the following investigations?

\begin{tabular}{|c|c|c|c|c|c|c|}
\hline & 0 & $1-10 X$ & $10-50 X$ & $50-300 X$ & $>300 \mathrm{X}$ & No ideas \\
\hline X-ray & & & & & & \\
\hline $\mathrm{CT}$ & & & & & & \\
\hline MRI & & & & & & \\
\hline US & & & & & & \\
\hline Radio-nuclide imaging & & & & & & \\
\hline
\end{tabular}

17)For each of the following statements, select the response that most closely matches your opinion.

\begin{tabular}{|c|c|c|c|c|c|c|}
\hline & & $\begin{array}{l}\text { Strongly } \\
\text { Disagree }\end{array}$ & Disagree & Neutral & Agree & $\begin{array}{c}\text { Strongly } \\
\text { Agree }\end{array}$ \\
\hline a) & $\begin{array}{l}\text { The policies and procedures on radiation precautions are clear } \\
\text { and easy to understand. }\end{array}$ & & & & & \\
\hline b) & $\begin{array}{l}\text { I feel confident about the steps I need to take when caring for } \\
\text { patients needing radiation precautions. }\end{array}$ & & & & & \\
\hline c) & $\begin{array}{l}\text { I know whom to contact if I have questions about what } \\
\text { radiation precautions are needed for a particular patient. }\end{array}$ & & & & & \\
\hline d) & $\begin{array}{l}\text { I feel I can clearly explain the radiation precautions needed to } \\
\text { my patients and their visitors. }\end{array}$ & & & & & \\
\hline e) & $\begin{array}{l}\text { I feel safe when caring for patients needing radiation } \\
\text { precautions. }\end{array}$ & & & & & \\
\hline f) & $\begin{array}{l}\text { I feel the institutional policies and procedures are based on } \\
\text { current regulations. }\end{array}$ & & & & & \\
\hline g) & $\begin{array}{l}\text { I feel confident the institution is carefully monitoring my } \\
\text { radiation exposure. }\end{array}$ & & & & & \\
\hline h) & $\begin{array}{l}\text { I feel that I will be called if I receive higher than normal } \\
\text { exposures. }\end{array}$ & & & & & \\
\hline i) & $\begin{array}{l}\text { I feel that working with patients receiving radiation will not } \\
\text { affect my ability to have a child. }\end{array}$ & & & & & \\
\hline
\end{tabular}

